\title{
SUBVENÇÕES E ASSISTÊNCIAS GOVERNAMENTAIS (SAG): EVIDENCIAÇÃO E RENTABILIDADE DAS MAIORES EMPRESAS BRASILEIRAS
}

\section{GOVERNMENTAL SUBVENTION AND ASSISTANCE (GSA): DISCLOSURE AND PROFITABILITY IN MAJOR BRAZILIAN COMPANIES}

\author{
Débora Queiroz Loureiro ${ }^{a}$; Alessandra Vasconcelos Gallon ${ }^{b}$; Márcia Martins Mendes De Luca ${ }^{c}$ \\ a Analista de Controladoria - M. Dias Branco S/A Industria e Comercio de Alimentos; \\ Graduação em Ciências Contábeis pela Federal do Ceará, UFC; Fortaleza, CE - Brasil; \\ E-mail:debora.queiroz@mdb.com.br \\ ${ }^{b}$ Professora Adjunto I da Universidade Federal do Ceará, UFC; \\ Doutorado em Engenharia de Produção pela Universidade Federal de Santa Catarina, UFSC \\ Fortaleza, CE-Brasil; E-mail: alegallon@terra.com.br \\ c Professora Adjunto IV da Universidade Federal do Ceará, UFC, \\ Resumo \\ Doutorado em Controladoria e Contabilidade pela Universidade de São Paulo - USP, \\ Fortaleza, CE-Brasil; E-mail: marciadeluca@ufc.br
}

O estudo tem o objetivo de investigar a divulgação das informações e os efeitos econômicos decorrentes do reconhecimento das Subvenções e Assistências Governamentais (SAG) nas demonstrações contábeis das maiores empresas abertas no Brasil, conforme Pronunciamento CPC 07, alterado pelo CPC 07(R1), em 2010. Foram analisadas 88 das 100 maiores companhias abertas listadas em Exame Melhores e Maiores 2010 (excluíram-se financeiras e seguradoras). O nível de evidenciação foi obtido a partir da Análise de Conteúdo das Notas Explicativas de 2008 e 2009, utilizando um check list, conforme disposições de divulgação do CPC 07, e os efeitos econômicos mensurados pelos índices ROA, ROE, ROS e ISAG de 2009. Constatou-se que as empresas apresentam nível de evidenciação considerado baixo, limitando-se, em média, a 30,4\% em 2008 e a 33,3\% em 2009, dos requisitos de divulgação do CPC 07. Quanto aos efeitos econômicos, constatou-se uma variação positiva da rentabilidade, especialmente do ROE, e uma expressiva participação das SAGs no capital próprio das empresas dos setores Têxtil e Papel e Celulose.

Palavras-chave: Subvenções e assistências governamentais, Evidenciação contábil, Desempenho econômico.

\begin{abstract}
This study investigates the disclosure and economic effects stemming from recognition of governmental subventions and assistances $(S A G)$ in accounting demonstrations by major Brazilian companies, according to Statement CPC 07, altered by CPC 07(R1), in 2010. We analyzed 88 of the 100 major companies listed on "Exame Melhores e Maiores 2010". Financial and insurance companies were not included. The levels of disclosure were obtained in a content analysis of explanatory notes of 2008 and 2009 by means of a check list, according to release dispositions in CPC 07, and economic effects measured by the ROA, ROE, ROS and ISAG indices of 2009. It was observed that companies present a disclosure level which is considered low. The level was limited to an average 30.4\% in 2008 and 33.3\% in 2009 of the CPC 07 release requisites. Concerning economic effects, was found a positive variation in profits, especially in ROE, and was observed an expressive participation of SAGs in the equity of companies of Textile and Pulp and Paper sectors.
\end{abstract}

Keywords: Subventions and governmental assistance, Accounting disclosure, Economic performance. 


\section{INTRODUÇÃ̃o}

A modernização da legislação societária brasileira, introduzida pelas Leis n ${ }^{\circ}$. 11.638/2007 e $n^{\circ} .11 .941 / 2009$ e por pronunciamentos técnicos emitidos pelo Comitê de Pronunciamentos Contábeis (CPC), significou um importante passo no processo de convergência das normais contábeis brasileiras aos padrões internacionais. Isso resultou em uma nova estrutura para as demonstrações contábeis, além de novos critérios de contabilização e de divulgação dos elementos patrimoniais e de resultados. Segundo Iudícibus et al (2010, p. 20), "o texto legal não só determinou essa convergência como produziu alterações na lei que impediam adoção de várias dessas normas internacionais". Os autores lembram ainda que a lei "fez expressa menção à figura do CPC e, o mais fundamental de tudo, determinou, de forma enfática, a segregação entre Contabilidade para fins de Demonstrações Contábeis e Contabilidade para fins fiscais" (IUDÍCIBUS et al, 2010, p. 20).

Dentre as inovações da Lei $\mathrm{n}^{\circ}$. 11.638/2007, destaca-se a revogação da reserva de capital "Doações e Subvenções para Investimentos". Essa alteração impacta na forma de registro contábil das Subvenções e Assistências Governamentais (SAGs), que deixam de ser reconhecidas como Reserva, no Patrimônio Líquido, para serem contabilizadas em conta de Resultado do Exercício, conforme nova ordem legal. Iudícibus et al (2010) salientam que isso não significa que as SAGs vão para o Resultado da mesma forma e nos mesmos períodos como anteriormente eram reconhecidas diretamente no Patrimônio Líquido, devendo ser reconhecidas no Resultado somente quando atendidas todas as condições de reconhecimento de qualquer receita. Nogueira Júnior, Jucá e Macedo (2010, p. 7) comentam que "essa nova prática de reconhecimento passa a produzir uma aproximação na relação lucro-caixa”.

Referida modificação é abordada no CPC 07 - emitido em 2008, modificado pelo CPC 07(R1) em 2010, aprovado pela Deliberação CVM no 646/2010 - com o objetivo de alinhar os padrões contábeis à International Accounting Standards (IAS) 20, que disciplina diversas modalidades de transações realizadas entre o setor público (governo) e o privado (empresas).

Segundo Taveira (2009), as SAGs são programas delineados, gerenciados e concedidos pelos governos (União, Estados, DF e Municípios) com o intuito de incrementar operações, atrair investimentos para determinadas regiões menos desenvolvidas e financiar a promoção de atividades de interesse público.

Formigoni (2008) observa que diante do impacto dos tributos no resultado contábil e no patrimônio das empresas, as concessões de incentivos fiscais - que fazem parte da espécie Subvenções - caracterizam-se como um importante e necessário campo de pesquisa nas áreas de Contabilidade e Administração.

Pelo fato de ainda ser recente a mudança nos critérios de registro e divulgação das SAGs nas demonstrações contábeis das empresas brasileiras, até o momento a temática foi abordada por poucos estudos acadêmicos, destacando-se Gruber e Gimenes (2008), Taveira (2009), Tonetto Filho e Fregonesi (2010) e Chagas et al (2010).

Assim, diante da proeminência quantitativa dos valores envolvidos pelas SAGs no país, este estudo procura responder ao seguinte questionamento: quais os efeitos da adoção do CPC 07 no nível de evidenciação e na rentabilidade das maiores empresas brasileiras de capital aberto? O estudo tem como objetivo geral verificar a divulgação das informações e os 
efeitos econômicos decorrentes do reconhecimento das SAGs nas demonstrações contábeis das maiores empresas brasileiras de capital aberto; e, como objetivos específicos, (i) identificar o número de empresas que evidenciaram o recebimento de SAG nas demonstrações contábeis, verificando os setores mais contemplados no período em análise; (ii) examinar o nível de atendimento dos requisitos de divulgação do CPC 07, observando os respectivos segmentos de listagem na BM\&FBovespa; (iii) analisar os efeitos da nova prática de reconhecimento da SAG nos indicadores econômicos das empresas, segundo os respectivos setores de atuação; e (iv) verificar se as empresas que receberam maiores recursos oriundos de SAG e apresentam melhor rentabilidade demonstram nível de evidenciação superior.

Pelo exposto, pode-se dizer que a presente pesquisa se justifica pelo fato de o tema ser pouco explorado no ambiente acadêmico, o que explica o reduzido número de estudos anteriores apresentados nesse trabalho, e pela relevância das SAGs no contexto atual das organizações empresariais, haja vista a representatividade dos valores envolvidos, tanto para o governo como para as empresas.

\section{SUBVENÇÃO E ASSISTÊNCIA GOVERNAMENTAIS (SAG) E ESTUDOS EMPÍRICOS ANTERIORES SOBRE O TEMA}

A preocupação dos organismos normatizadores de práticas contábeis no Brasil com questões relacionadas à $\mathrm{SAG}$, de convergência aos padrões internacionais de contabilidade, conduziu à revogação da reserva de capital Doações e Subvenções para Investimentos e à criação da Reserva de Incentivos Fiscais pela Lei $n^{\circ}$. 11.638/2007, que inclui na Lei $n^{\circ} .6 .404 / 1976$ o artigo 195-A, do seguinte teor:

\footnotetext{
A assembleia geral poderá, por proposta dos órgãos de administração, destinar para a reserva de incentivos fiscais a parcela do lucro líquido decorrente de doações ou subvenções governamentais para investimentos, que poderá ser excluída da base de cálculo do dividendo obrigatório.
}

Cabe ressaltar que em estudo desenvolvido por Alves, Carvalho e Slomski (2004), anterior às mudanças na legislação societária brasileiras sobre as SAGs, ao identificar e comparar a posição dos US-GAAP, IASB e CFC quanto aos critérios de reconhecimento das contribuições, doações e subvenções nas entidades do terceiro setor, considerando a sua importância para a avaliação do desempenho dessas organizações, os autores constataram a falta de uniformidade dos critérios adotados pelas normas contábeis norte-americanas (US-GAAP), internacionais (IASB) e brasileiras (CFC), em especial com relação às normas do CFC.

No intuito de esclarecer sobre o tratamento contábil das SAGs no Brasil após a edição da Lei n ${ }^{\circ}$. 11.638/2007, a Comissão de Valores Mobiliários (CVM) editou a Instrução no . 469/2008, e respectiva nota explicativa, segundo a qual as SAGs não mais poderiam ser registradas como Reserva de Capital, porquanto devem refletir tão-somente as contribuições dos acionistas para formação ou aumento do capital. Assim, as SAGs deveriam ser registradas como redução do custo do Ativo, caso se referirem a um ativo não monetário, ou, nos demais casos, como receita a ser apropriada ao Resultado.

Para regulamentar esse novo registro, foi emitido o Pronunciamento Técnico CPC 07, aprovado pela Norma Brasileira de Contabilidade Técnica (NBCT) 19.4 - Subvenção e Assistência Governamentais, por meio da Resolução n ${ }^{0}$. 1.143/2008, do Conselho Federal de Contabilidade (CFC), e pela Deliberação nº. 555/2008, da CVM. Esses normativos dispõem 
sobre alteração do tratamento contábil para as doações e subvenções. A partir do exercício social de 2008, as SAGs recebidas pelas empresas devem ser registradas em conta de Resultado do Exercício como receita, e não mais como incremento da Reserva de Capital. Cabe informar que em 2010, o CPC 07 foi alterado pelo CPC 07(R1), regulamentado pela Deliberação CVM n ${ }^{\circ}$. 646/2010, trazendo algumas modificações, principalmente quanto aos requisitos de divulgação das SAGs.

O CPC 07 (2008) não segrega formalmente as modalidades de subvenção para investimento e custeio, isso porque o tratamento contábil dispensado nas referidas modalidades deve ser o mesmo, ou seja, o trânsito pelo Resultado do Exercício. Interessante ressaltar que, conquanto a norma brasileira tenha como essência as disposições do padrão internacional (IAS 20), tornou-se necessária a inclusão de algumas especificidades no texto do normativo, já que as isenções, reduções e incentivos tributários brasileiros são peculiares, embora não percam a essência de subvenção governamental.

O CPC 07(R1) (2010) dá as seguintes definições para assistência e subvenção governamentais, respectivamente:

\begin{abstract}
Assistência governamental é a ação de um governo destinada a fornecer benefício econômico específico a uma entidade ou a um grupo de entidades que atendam a critérios estabelecidos. Subvenção governamental é uma assistência governamental geralmente na forma de contribuição de natureza pecuniária, mas não só restrita a ela, concedida a uma entidade normalmente em troca do cumprimento passado ou futuro de certas condições relacionadas às atividades operacionais da entidade.
\end{abstract}

Conforme elucidam Chagas et al (2010, p. 9), a subvenção governamental é uma espécie de assistência governamental, "diferindo apenas na forma de contribuição, enquanto a subvenção governamental, geralmente, tem natureza pecuniária, a assistência governamental pode ser realizada através de outras ações de natureza não pecuniária”.

Para justificar a contabilização da SAG como receita, na Demonstração do Resultado do Exercício (DRE) nos períodos ao longo dos quais a empresa deve reconhecer os custos relacionados à SAG que são objeto de compensação, o CPC 07(R1) (2010) apresenta os seguintes argumentos: (i) é recebida de uma fonte que não os acionistas e deriva de ato de gestão em benefício da entidade, não devendo, portanto, ser creditada diretamente no Patrimônio Líquido, mas, sim, reconhecida como receita nos períodos apropriados; (ii) raramente é gratuita e a entidade ganha efetivamente essa receita quando cumpre as regras das SAGs e determinadas obrigações; e (iii) assim como os tributos são despesas reconhecidas na DRE, a SAG é, em essência, uma extensão da política fiscal, devendo também ser reconhecida no Resultado. Entretanto, Alencar, Pimentel e Mota Filho (2010) advertem que alguns pesquisadores não acham correta a nova forma de reconhecimento da $\mathrm{SAG}$, já que essa riqueza não foi gerada pela entidade, mas oriunda de um incentivo governamental.

A recente mudança nos critérios de registro e divulgação das SAGs nas demonstrações contábeis das empresas brasileiras foi tema de algumas pesquisas, destacando-se os estudos de Gruber e Gimenes (2008), Taveira (2009), Tonetto Filho e Fregonesi (2010) e Chagas et al (2010).

No estudo de Gruber e Gimenes (2008) sobre a estrutura de capital e a rentabilidade de duas cooperativas que operam no setor de alimentos, em comparação com duas empresas de capital aberto que operam no mesmo mercado, foi possível constatar, com base no Índice de Subvenção e Assistência Governamental (ISAG) — relação entre SAG e o Patrimônio Líquido 
—, a importância e a relevância de doações e subvenções governamentais na composição do capital nas cooperativas, como integrantes do patrimônio.

O estudo de Taveira (2009) analisou se as companhias abertas listadas nos segmentos Nível 1, Nível 2 e Novo Mercado da BM\&FBovespa observaram as orientações sobre o registro e a divulgação das SAGs nas demonstrações contábeis de 2008, podendo constatar que as 158 companhias pesquisadas não efetuaram o disclosure de forma satisfatória, estando em desacordo com o CPC 07.

Iudícibus et al (2010) afirmam que, para algumas empresas, as operações que envolvem SAG são significativas no Resultado do Exercício, o que pode ser relevante na análise do desempenho econômico empresarial. Essa afirmação corrobora os resultados de Tonetto Filho e Fregonesi (2010) que, ao analisar a variação dos níveis de endividamento e liquidez das empresas do setor de alimentos processados, em 2007, observaram que no caso da empresa $\mathrm{M}$. Dias Branco S. A., uma das principais causas da variação dos índices foi o reconhecimento da SAG no resultado da companhia.

O trabalho de Chagas et al (2010) teve o intuito de verificar se as SAGs auferidas pelas Organizações da Sociedade Civil de Interesse Público (OSCIP) da Paraíba e do Rio Grande do Norte, no período de 2008, foram evidenciadas nas respectivas demonstrações contábeis conforme o CPC 07 e a NBC T 19.14 do CFC. Os resultados do estudo apontam que, apesar da exigência de evidenciação das SAGs, muitas entidades ainda não o fazem.

Pelo exposto em estudos nacionais anteriores, esta pesquisa se diferencia das demais citadas por abordar tanto o nível de evidenciação sobre as SAGs recomendado pelo CPC 07, como o efeito do novo tratamento contábil no desempenho econômico das empresas, o que, por si só, justifica a sua realização. Destaca-se que o exame do nível de evidenciação da SAG compreendeu a análise por segmento de listagem na BM\&FBovespa, enquanto o exame do efeito econômico do novo tratamento contábil, por meio dos indicadores ROA, ROE, ROS e ISAG, compreendeu a análise por setor de atuação.

\section{METODOLOGIA}

A presente pesquisa foi delineada em função do objetivo, dos procedimentos e da abordagem do problema. Quanto aos objetivos, trata-se de um estudo descritivo, a fim de verificar o nível de divulgação das informações e os efeitos econômicos das SAGs nas demonstrações contábeis das maiores empresas brasileiras de capital aberto, realizado por meio de pesquisa documental, com abordagem qualitativa dos dados.

Para responder à questão de pesquisa, a seleção das empresas que compuseram a amostra se deu a partir da população das 100 maiores companhias de capital aberto de 2009 listadas na edição Melhores e Maiores de 2010 da Revista Exame, segundo o valor de mercado, excluindose as 12 empresas financeiras e de seguros, por adotarem normas contábeis peculiares, reunindo uma amostra das 88 maiores companhias abertas brasileiras não-financeiras de 2009.

Após a definição do universo amostral do estudo, partiu-se para a análise do conteúdo das demonstrações financeiras padronizadas (DFP) - Balanço Patrimonial, Demonstração do Resultado do Exercício e Notas Explicativas - das empresas referentes aos exercícios de 2008 e 2009 divulgadas no portal eletrônico da CVM. Quanto à Análise de Conteúdo, observaram-se 
as três fases do método, conforme Bardin (2004): (1) pré-análise; (2) exploração do material, que, nesse caso, consistiu das DFPs; e (3) tratamento dos resultados, inferência e interpretação. Para garantir maior confiabilidade aos resultados, uma primeira análise dos documentos foi realizada por um dos pesquisadores, sendo posteriormente revisada pelos outros dois.

O primeiro passo da análise consistiu em verificar se as empresas evidenciaram em Notas Explicativas o recebimento de SAG em cada um dos dois períodos em análise. Em caso positivo, o incentivo foi classificado como Federal (F), Estadual (E) e/ou Municipal (M), dependendo da origem do recurso público. Além disso, em todas as empresas da amostra que evidenciaram o recebimento de SAG foi analisado o nível de divulgação em Notas Explicativas, por meio de um check list contendo os itens requeridos no CPC 07 (2008), conforme exibe o Quadro 1, já que nos exercícios analisados o CPC 07(R1) (2010), que prescreve recomendação apenas para os itens 1, 2 e 3, ainda não havia sido editado.

\begin{tabular}{|c|l|}
\hline Item & \multicolumn{1}{|c|}{ Informação a ser divulgada pelas empresas (CPC 07, 2008) } \\
\hline 1 & $\begin{array}{l}\text { A política contábil adotada para as subvenções governamentais, incluindo os métodos de apresentação adotados } \\
\text { nas demonstrações financeiras }\end{array}$ \\
\hline 2 & $\begin{array}{l}\text { A natureza das subvenções governamentais ou das assistências governamentais e os montantes reconhecidos, bem } \\
\text { como a indicação de outras formas de assistência governamental que tenha beneficiado diretamente a entidade }\end{array}$ \\
\hline 3 & As condições a serem regularmente satisfeitas, ligadas à assistência governamental que tenha sido reconhecida \\
\hline 4 & O descumprimento de condições relativas às subvenções ou a existência de outras contingências \\
\hline 5 & O prazo durante o qual a subvenção permanecerá na entidade \\
\hline 6 & Eventuais subvenções a reconhecer contabilmente, após cumpridas as condições contratuais \\
\hline 7 & As premissas consideradas no cálculo do valor justo exigido pela regulamentação contábil \\
\hline 8 & $\begin{array}{l}\text { As informaçóes relativas às parcelas aplicadas em fundos de investimentos regionais e às reduções ou isenções de } \\
\text { tributos em áreas incentivadas }\end{array}$ \\
\hline
\end{tabular}

Quadro 1: Itens de divulgação das SAGs para verificação em Notas Explicativas

Fonte: Adaptado do CPC 07 (2008).

Segundo o Quadro 1, para a análise do nível de evidenciação o check list abrangeu os itens de divulgação das SAGs conforme o CPC 07 (2008). Enquanto isso, para atestar o nível de divulgação optou-se pela utilização de dois diferentes pesos, como unidade de análise, para classificar e quantificar o nível da evidenciação relacionado a cada item de divulgação. Assim, aplicou-se zero (0) para Evidenciação Parcial ou Nula e um (1) para Evidenciação Total, nas Notas Explicativas, de 2008 e 2009, das empresas que admitiram o recebimento de SAG nos dois períodos em análise. Consideraram-se como Evidenciação Total somente os dados divulgados de forma completa, segundo os requisitos do CPC 07. Atribuiu-se Evidenciação Parcial ou Nula aos dados cuja evidenciação não atendia integralmente as informações a serem divulgadas para cada um dos aos itens estabelecidos no CPC 07 ou quando não houve divulgação do respectivo item pela empresa, respectivamente. Especificamente em relação aos itens de divulgação 4, 6, 7 e 8 , descumprimento de condições, subvenções a receber, valor justo e parcelas aplicadas em fundos de investimentos e reduções de isenções em áreas incentivadas, respectivamente (Quadro 1), cabe ressaltar que ainda que tais itens não fossem aplicáveis, tal fato deveria ser evidenciado pela empresa, conforme preconiza o CPC 07.

Para cada item (informação a ser evidenciada, conforme Quadro 1) atribuiu-se uma pontuação: Evidenciação Total, 1; Evidenciação Parcial ou Nula, 0. Portanto, cada empresa poderia obter o máximo de oito (8) pontos, levando-se em conta a possibilidade de pontuação 
máxima (1 ponto) em cada um dos oito itens investigados.

Com o intuito de analisar os efeitos econômicos decorrentes do novo critério de reconhecimento contábil das SAGs nas demonstrações contábeis das empresas, foram utilizados os índices apresentados no Quadro 2.

\begin{tabular}{|c|c|c|}
\hline Índice & Fórmula de cálculo & Descrição \\
\hline ROA (Return on Assets) & Lucro Líquido / Ativo Total & $\begin{array}{c}\text { Indica a produtividade ou capacidade de } \\
\text { retorno do Ativo }\end{array}$ \\
\hline ROE (Return on Equities) & Lucro Líquido / Patrimônio Líquido & $\begin{array}{c}\text { Indica o retorno obtido pelo acionista } \\
\text { sobre o capital próprio investido }\end{array}$ \\
\hline ROS (Return on Sales) & Lucro Líquido / Receita Total & $\begin{array}{c}\text { Indica o retorno obtido pela companhia } \\
\text { sobre a Receita Total }\end{array}$ \\
\hline $\begin{array}{c}\text { ISAG (Índice de Subvenção e } \\
\text { Assistência Governamentais) }\end{array}$ & $\begin{array}{c}\text { Subvenção e Assistência Governamentais } \\
\text { / Patrimônio Líquido }\end{array}$ & $\begin{array}{c}\text { Indica quanto do Patrimônio Líquido é } \\
\text { formado por SAG }\end{array}$ \\
\hline
\end{tabular}

Quadro 2: Indicadores econômicos utilizados na análise

Fonte: Adaptado de Gruber e Gimenes (2008), Santos (2009) e Iudícibus (2010).

Para a análise do impacto na rentabilidade e da representatividade do ISAG, as empresas que evidenciaram o recebimento de SAG nas Notas Explicativas dos dois períodos analisados foram agrupadas de acordo com o setor de atuação, proporcionando o cálculo de índices médios. O exercício de 2009 foi selecionado como referência por apresentar maior representatividade das SAGs nas empresas, comparativamente ao exercício de 2008. Para a consecução da análise econômica e do ISAG, apura-se uma comparação entre a situação atual, em que a SAG é considerada no Resultado do Exercício, e uma situação sem considerar o incentivo no Resultado da empresa, ou seja, excluindo o valor da SAG do Resultado do Exercício. Dessa forma, consegue-se analisar os efeitos econômicos das SAGs no desempenho empresarial e avaliar a representatividade do ISAG por setor de atuação.

Por fim, o último passo da análise consistiu em verificar se as empresas que possuíam os maiores valores de SAG e maior rentabilidade representavam as mesmas com melhores níveis de evidenciação. Para tanto, foram analisadas as informações do ano de 2009, levando em conta o setor de atuação das empresas e o nível de governança, conforme listagem nos segmentos diferenciados da BM\&FBovespa. A escolha do período justifica-se pelos motivos já apresentados anteriormente.

\section{ANÁLISE DOS RESULTADOS}

\subsection{Empresas Contempladas com SAG}

Inicialmente, cabe informar que o Relatório de Audiência Pública do CPC 07 (2008), informa (item 4.7) que é de responsabilidade da empresa e de seus auditores a verificação, via documentos e outros meios considerados próprios, do cumprimento das orientações sobre o tratamento contábil e a divulgação das informações relativas à SAG nas demonstrações contábeis. Assim, nesta pesquisa considera-se que receberam SAG as empresas que efetivamente fizeram menção ao incentivo nas Notas Explicativas às demonstrações contábeis dos períodos em análise.

A Tabela 1 mostra a distribuição quantitativa das empresas que receberam e das que não 
receberam SAG em 2008 e 2009, qualificando o incentivo recebido em Federal e/ou Estadual, conforme cada caso.

Tabela 1: Distribuição quantitativa e proporcional das empresas por situação em relação a SAG/Origem

\begin{tabular}{l|c|c|c|c}
\hline \multirow{2}{*}{ Situação / Origem da SAG } & \multicolumn{2}{|c|}{$\mathbf{2 0 0 9}$} & \multicolumn{2}{c}{$\mathbf{2 0 0 8}$} \\
\cline { 2 - 5 } & Quantidade & Proporção (\%) & Quantidade & Proporção (\%) \\
\hline Não informou ou não recebeu SAG & 43 & 48,9 & 42 & 47,7 \\
\hline Recebeu SAG Federal & 34 & 38,6 & 33 & 37,5 \\
\hline Recebeu SAG Estadual & 5 & 5,7 & 6 & 6,8 \\
\hline Recebeu SAG Federal e Estadual & 6 & 6,8 & 7 & 8,0 \\
\hline TOTAL & $\mathbf{8 8}$ & $\mathbf{1 0 0 , 0}$ & $\mathbf{8 8}$ & $\mathbf{1 0 0 , 0}$ \\
\hline
\end{tabular}

Fonte: Dados da pesquisa.

Conforme se observa na Tabela 1, das 88 empresas pesquisadas, 45 em 2009 e 46 em 2008 evidenciaram em Notas Explicativas haver recebido algum tipo de SAG, representando respectivamente $51,1 \%$ e $52,3 \%$ da amostra, o que ratifica a importância desta pesquisa. Esses resultados corroboram os de Taveira (2009), segundo o qual 54\% das companhias listadas nos níveis de governança da BM\&FBovespa foram contemplados com alguma modalidade de SAG no exercício de 2008 (exercício social anterior ao CPC 07 R1, publicado em 2010).

Nos dois exercícios analisados, nota-se que a maioria das empresas recebeu SAGs oriundas da União, com destaque para os incentivos nos impostos federais, cuja maior parte corresponde a renúncia fiscal do Imposto de Renda de Pessoa Jurídica (IRPJ). Destaca-se ainda que nenhuma empresa evidenciou o recebimento de SAG Municipal e que, em ambos os períodos, há empresas que acumularam o recebimento de SAG Federal e Estadual, no caso, Braskem, CSN, Grendene, Guararapes, M. Dias Branco, Vivo e WEG.

Em termos comparativos, torna-se interessante elucidar que quando Rech (2006) analisou a aderência das entidades do setor agropecuário às IFRS referentes às SAGs no âmbito do Estado do Mato Grosso, o autor constatou que 51,3\% das 39 entidades rurais pesquisadas indicaram possuir SAGs.

O trabalho realizado anteriormente as exigências do CPC 07 demonstrou que as empresas rurais que evidenciaram ter recebido $\mathrm{SAG}$, apresentaram forma diferenciada de tratamento quanto à sua apresentação nas demonstrações financeiras, a saber: $12,8 \%$ das entidades não apresentam no Balanço Patrimonial e na Demonstração de Resultados, destacando apenas nas Notas Explicativas; e 38,5\% das entidades apresentaram as SAGs tanto no Balanço Patrimonial como na Demonstração de Resultados (REECH, 2006). Na presente investigação, levando em conta as maiores empresas abertas no Brasil constatou-se percentuais de informação sobre o recebimento das SAGs em Notas Explicativas semelhantes, no caso 51,1\% em 2008 e 52,3\% em 2009, conforme apresentado na Tabela 1.

A Tabela 2 exibe a distribuição quantitativa das 88 empresas e daquelas que receberam SAG, por setor de atuação, com os respectivos valores do incentivo considerados no Resultado do Exercício. 
Tabela 2: Distribuição quantitativa das empresas, por setor de atuação e por situação em relação a SAG, com respectivos montantes

\begin{tabular}{|c|c|c|c|c|c|}
\hline \multirow[b]{2}{*}{ Setor de atuação } & \multirow[b]{2}{*}{ Quantidade } & \multicolumn{2}{|l|}{2009} & \multicolumn{2}{|c|}{2008} \\
\hline & & $\begin{array}{c}\mathrm{N}^{\circ} \text { de empresas } \\
\text { contempladas } \\
\text { com SAG }\end{array}$ & $\begin{array}{c}\text { Valor } \\
\text { (R\$ Mil) }\end{array}$ & $\begin{array}{c}\mathrm{N}^{\mathrm{o}} \text { de empresas } \\
\text { contempladas } \\
\text { com SAG }\end{array}$ & $\begin{array}{c}\text { Valor } \\
\text { (R\$ Mil) }\end{array}$ \\
\hline Energia & 23 & 16 & 996.245 & 14 & 962.740 \\
\hline Serviços & 12 & 2 & 24.995 & 4 & 2.332 \\
\hline Bens de Consumo & 7 & 6 & 324.437 & 6 & 366.684 \\
\hline Telecomunicações & 7 & 5 & 161.073 & 5 & 207.735 \\
\hline Indústria da Construção & 7 & - & - & 1 & - \\
\hline Transporte & 5 & 2 & 28.439 & 2 & 3.623 \\
\hline Siderurgia e Metalurgia & 4 & 4 & 26.950 & 4 & 46.172 \\
\hline Varejo & 4 & - & - & - & - \\
\hline Química e Petroquímica & 3 & 2 & 128.324 & 2 & 64.776 \\
\hline Mineração & 3 & 1 & 368 & 1 & 227 \\
\hline Papel e Celulose & 3 & 1 & 37.715 & 1 & - \\
\hline Autoindústria & 2 & 2 & 26.508 & 2 & 26.129 \\
\hline Têxtil & 2 & 2 & 193.011 & 2 & 151.210 \\
\hline Bens de Capital & 1 & 1 & 2.275 & 1 & 22.630 \\
\hline Eletroeletrônico & 1 & 1 & 4.358 & 1 & 5.117 \\
\hline Produção Agropecuária & 1 & - & - & - & - \\
\hline Holding & 1 & - & - & - & - \\
\hline Indústria Digital & 1 & - & - & - & - \\
\hline Diversos & 1 & - & - & - & - \\
\hline TOTAL & 88 & 45 & 1.954 .698 & 46 & 1.859 .375 \\
\hline
\end{tabular}

Fonte: Dados da pesquisa.

$\mathrm{Na}$ Tabela 2, verifica-se que em termos monetários, as empresas dos setores Têxtil, Energia, Bens de Consumo, Telecomunicações e Química e Petroquímica foram as que, em média, e nessa ordem, mais receberam SAG nos períodos analisados. Observa-se também que, apesar da ligeira queda no número de empresas que recebeu SAG, de 2008 para 2009 (de 46 para 45), o valor total recebido por elas elevou-se de $\mathrm{R} \$ 1.859 .375 .000,00$ para 1.954.698.000,00 no período.

O destaque do setor de Energia, representando mais de $50 \%$ do total recebido pelas empresas pesquisadas, se deve ao fato de a Petrobras haver evidenciado nas demonstrações contábeis o recebimento de $\mathrm{R} \$ 557.185 .000,00$ em 2008 e $\mathrm{R} \$ 554.447 .000,00$ em 2009, devidamente considerados no Resultado dos respectivos exercícios contábeis. Quanto ao setor Têxtil, que apresentou o maior volume médio de recursos por empresa, destaca-se a Grendene, que evidenciou o recebimento de R\$105.410.000,00 em 2008 e R\$ 157.100.000,00 em 2009. As cinco empresas com maior volume de SAG são Petrobras, Ambev, Grendene, Coelba e M. Dias Branco. Esses resultados corroboram aqueles obtidos por Tonetto Filho e Fregonesi (2010) que, ao analisarem a variação dos níveis de endividamento e liquidez das empresas do setor de alimentos processados, em 2007, observaram que na M. Dias Branco uma das principais causas da variação dos índices foi o reconhecimento da SAG no Resultado do Exercício. As empresas dos setores de Indústria da Construção e Papel e Celulose evidenciaram o recebimento de SAG em 2008, mas não divulgaram o valor do incentivo obtido, enquanto as dos setores Varejo, Produção Agropecuária, Holding, Indústria Digital e Diversos não receberam SAG em 2008 e 
2009.

A Tabela 3 apresenta a distribuição quantitativa das empresas por segmento de listagem na BM\&FBovespa e por situação em relação ao recebimento de SAG em 2008 e em 2009. Essa análise será considerada para avaliação do nível das informações sobre SAG nas Notas Explicativas.

Tabela 3: Distribuição quantitativa das empresas, por segmento de listagem na BM\&FBovespa e por situação em relação ao recebimento de SAG

\begin{tabular}{|c|c|c|c|c|c|}
\hline \multirow{3}{*}{ Segmento } & \multirow{3}{*}{ Quantidade } & \multicolumn{2}{|c|}{2009} & \multicolumn{2}{|c|}{2008} \\
\hline & & \multicolumn{2}{|c|}{ Quantidade } & \multicolumn{2}{|c|}{ Quantidade } \\
\hline & & Receberam & Não Receberam & Receberam & Não receberam \\
\hline Nível 1 & 13 & 9 & 4 & 9 & 4 \\
\hline Nível 2 & 6 & 1 & 5 & 1 & 5 \\
\hline Novo Mercado & 42 & 15 & 27 & 17 & 25 \\
\hline Outras & 27 & 20 & 7 & 19 & 8 \\
\hline TOTAL & 88 & 45 & 43 & 46 & 42 \\
\hline
\end{tabular}

Fonte: Dados da pesquisa.

Sobre os segmentos de listagem das empresas, destaca-se que nos últimos anos a BM\&FBovespa implementou algumas iniciativas para garantir melhores práticas de governança corporativa, destacando-se a criação dos três segmentos. Segundo a BM\&FBovespa (2010), as empresas listadas nesses segmentos ampliam os direitos societários dos acionistas minoritários e aumentam a transparência, com divulgação de maior volume de informações e de melhor qualidade, facilitando o acompanhamento de sua performance pelo mercado. As empresas que não se enquadram nesses segmentos não possuem regras explícitas de evidenciação além dos normativos contábeis (evidenciação compulsória). Em conformidade com as regras de adesão aos segmentos de listagem, conjetura-se que as empresas do Novo Mercado devem apresentar maior nível de disclosure que as do Nível 2 que, por sua vez, devem ser mais transparentes do que as do Nível 1.

Conforme evidenciado na Tabela 3, o Novo Mercado é o segmento de listagem preponderante, reunindo 42 empresas (ou 47,7\% do total pesquisado). Considerando-se o número de empresas que efetivamente receberam SAG nos períodos analisados, observa-se que o Novo Mercado foi o segmento que reuniu o maior número de empresas, totalizando 19 em 2008 e 17 em 2009.

Cabe esclarecer que a partir deste ponto da pesquisa, todas as análises consideram somente as empresas que efetivamente receberam e evidenciaram informações sobre SAG nas Notas Explicativas, totalizando 46 em 2008 e 45 em 2009, conforme apresentado na Tabela 2.

\subsection{Nível de Atendimento dos Requisitos de Divulgação do CPC 07 pelas Empresas Contempladas com SAG}

Para melhor compreensão da Análise de Conteúdo, o Quadro 3 exibe alguns exemplos de 
informações divulgadas nas Notas Explicativas das empresas, conforme check list apresentado no Quadro 1, consideradas como Evidenciação Total, por atenderem completamente aos requisitos de divulgação do CPC 07.

\begin{tabular}{|c|c|}
\hline Item & Descrição \\
\hline 1 & $\begin{array}{l}\text { As subvenções e assistências governamentais são reconhecidas quando há razoável segurança de } \\
\text { que foram cumpridas as condições estabelecidas pelos governos estaduais do Ceará e da Bahia e de } \\
\text { que são auferidas (Nota 14). São registradas como receita no Resultado durante o período necessário } \\
\text { para confrontar com a despesa que a subvenção ou assistência governamental pretende compensar e, } \\
\text { posteriormente, são destinadas para Reserva de Incentivos Fiscais no Patrimônio Líquido (Grendene } \\
\text { - N. E. de 2009) }\end{array}$ \\
\hline 2 & $\begin{array}{l}\text { No exercício de } 2009 \text {, foram destinados do Resultado R\$ } 539.995 \text { mil referentes ao incentivo } \\
\text { para subvenção de investimentos no Nordeste e na Amazônia, no âmbito da Superintendência de } \\
\text { Desenvolvimento do Nordeste (Sudene) e da Superintendência de Desenvolvimento da Amazônia } \\
\text { (Sudam), e R\$ } 14.452 \text { mil referentes à realização de parte dos depósitos para reinvestimentos com } \\
\text { recursos próprios (Petrobras - N. E. de 2009) }\end{array}$ \\
\hline 3 & $\begin{array}{l}\text { Para incremento de valor financiado, a companhia e suas controladas observam todas as exigências } \\
\text { para obtenção desse tipo de incentivo, a saber: a) faturamento bruto incremental mensal; b) ICMS } \\
\text { incremental mensal; e c) número de empregos diretos incremental (Randon - N. E. de 2009) }\end{array}$ \\
\hline 4 & $\begin{array}{l}\text { Até então, a companhia e controladas não descumpriram qualquer condição que impeça a continuidade } \\
\text { do direito de usufruir dos benefícios das subvenções governamentais recebidas (M. Dias Branco - N. } \\
\text { E. de 2009) }\end{array}$ \\
\hline 5 & $\begin{array}{l}\text { Esses incentivos, concedidos pela Sudene, consistem na isenção ou redução de } 75 \% \text { de imposto de } \\
\text { renda sobre resultados apurados em cada unidade fabril, até o ano-base } 2017 \text { (Guararapes - N. E. de } \\
\text { 2008) }\end{array}$ \\
\hline 6 & $\begin{array}{l}\text { A companhia apresentou à Sudene pedido de idêntico incentivo fiscal de redução do imposto de } \\
\text { renda para a linha } 2 \text { de celulose de Mucuri (expansão), que, se concedido, possibilitará a utilização do } \\
\text { benefício para os produtos da linha } 2 \text { (cumulativamente com o já referido para a linha 1), a partir do } \\
\text { exercício de } 2009 \text {, pelo prazo de dez anos (Suzano - N. E. de 2008). }\end{array}$ \\
\hline 7 & $\begin{array}{l}\text { A subsidiária Sadia recebeu em doação um terreno localizado em Pernambuco, cujo valor justo em } \\
\text { 31/12/2009 é de R } \$ 4.139 .000,00 \text {. A doação está condicionada à construção de uma unidade produtiva, } \\
\text { gerando empregos e desenvolvimento econômico e social na região (BRF - N. E. de 2009). }\end{array}$ \\
\hline 8 & $\begin{array}{l}\text { No caso da unidade de moagem de trigo, o incentivo consiste no diferimento do pagamento de parte } \\
\text { do ICMS devido sobre a aquisição do trigo em grão e, ao final do prazo, na quitação de } 63,75 \% \text { desse } \\
\text { ICMS com recursos do Fundo de Desenvolvimento Industrial (FDI), correspondentes à subvenção } \\
\text { para investimento concedida (M. Dias Branco - N. E. de 2009). }\end{array}$ \\
\hline
\end{tabular}

Quadro 3: Exemplificação das informações divulgadas pelas empresas conforme CPC 07 (2008) consideradas como Evidenciação Total

Fonte: Dados da pesquisa.

Com o intuito de atender ao segundo objetivo específico da pesquisa, a Tabela 4 exibe a quantidade e a proporção (\%) de empresas que apresentaram Evidenciação Parcial ou Nula e Evidenciação Total para cada um dos itens de divulgação do CPC 07, bem como demonstra o nível de evidenciação médio das empresas, nos dois períodos de análise. 
Subvenções e Assistências Governamentais (SAG):

Evidenciação e Rentabilidade das Maiores Empresas Brasileiras

Tabela 4: Nível de atendimento dos itens de divulgação do CPC 07 das empresas que receberam SAG no período analisado

Item evidenciado / Quantidade / Proporção (\%) de empresas - 2008

\begin{tabular}{c|c|c|c|c|c|c|c|c|c}
\hline Nível de evidenciação & $\mathbf{1}$ & $\mathbf{2}$ & $\mathbf{3}$ & $\mathbf{4}$ & $\mathbf{5}$ & $\mathbf{6}$ & $\mathbf{7}$ & $\mathbf{8}$ & Média \\
\hline Evidenciação Parcial ou Nula & 11 & 18 & 22 & 45 & 30 & 45 & 45 & 41 & 32 \\
Evidenciação Total & 35 & 28 & 24 & 1 & 16 & 1 & 1 & 5 & 14 \\
\hline Total & $\mathbf{4 6}$ & $\mathbf{4 6}$ & $\mathbf{4 6}$ & $\mathbf{4 6}$ & $\mathbf{4 6}$ & $\mathbf{4 6}$ & $\mathbf{4 6}$ & $\mathbf{4 6}$ & $\mathbf{4 6}$ \\
\hline Evidenciação Parcial ou Nula (\%) & 23,9 & 39,1 & 47,8 & 97,8 & 65,2 & 97,8 & 97,8 & 89,1 & 69,6 \\
Evidenciação Total (\%) & 76,1 & 60,9 & 52,2 & 2,2 & 34,8 & 2,2 & 2,2 & 10,9 & 30,4 \\
\hline Total (\%) & $\mathbf{1 0 0 , 0}$ & $\mathbf{1 0 0 , 0}$ & $\mathbf{1 0 0 , 0}$ & $\mathbf{1 0 0 , 0}$ & $\mathbf{1 0 0 , 0}$ & $\mathbf{1 0 0 , 0}$ & $\mathbf{1 0 0 , 0}$ & $\mathbf{1 0 0 , 0}$ & $\mathbf{1 0 0 , 0}$ \\
\hline
\end{tabular}

Pontuação máxima possível das empresas em 2008 (46 empresas x 8 pontos): 368 pontos

Pontuação atingida pelas empresas em 2008: 14 pontos ou $3,8 \%$

Item evidenciado / Quantidade / Proporção (\%) de empresas - 2009

\begin{tabular}{c|c|c|c|c|c|c|c|c|c}
\hline Nível de evidenciação & $\mathbf{1}$ & $\mathbf{2}$ & $\mathbf{3}$ & $\mathbf{4}$ & $\mathbf{5}$ & $\mathbf{6}$ & $\mathbf{7}$ & $\mathbf{8}$ & Média \\
\hline Evidenciação Parcial ou Nula & 11 & 14 & 19 & 44 & 30 & 44 & 42 & 37 & 30 \\
Evidenciação Total & 34 & 31 & 26 & 1 & 15 & 1 & 3 & 8 & 15 \\
\hline Total & $\mathbf{4 5}$ & $\mathbf{4 5}$ & $\mathbf{4 5}$ & $\mathbf{4 5}$ & $\mathbf{4 5}$ & $\mathbf{4 5}$ & $\mathbf{4 5}$ & $\mathbf{4 5}$ & $\mathbf{4 5}$ \\
\hline Evidenciação Parcial ou Nula (\%) & 24,4 & 31,1 & 42,2 & 97,8 & 66,7 & 97,8 & 93,3 & 82,2 & 66,7 \\
Evidenciação Total (\%) & 75,6 & 68,9 & 57,8 & 2,2 & 33,3 & 2,2 & 6,7 & 17,8 & 33,3 \\
\hline Total (\%) & $\mathbf{1 0 0 , 0}$ & $\mathbf{1 0 0 , 0}$ & $\mathbf{1 0 0 , 0}$ & $\mathbf{1 0 0 , 0}$ & $\mathbf{1 0 0 , 0}$ & $\mathbf{1 0 0 , 0}$ & $\mathbf{1 0 0 , 0}$ & $\mathbf{1 0 0 , 0}$ & $\mathbf{1 0 0 , 0}$ \\
\hline
\end{tabular}

Pontuação máxima possível das empresas em 2009 (45 empresas x 8 pontos): 360 pontos

Pontuação atingida pelas empresas em 2009: 15 pontos ou $4,2 \%$

Fonte: Dados da pesquisa.

Conforme Tabela 4, nota-se que o nível de atendimento dos requisitos de divulgação do CPC 07 é baixo nos dois períodos analisados, sendo possível observar uma pequena melhora em 2009 (de 30,4\% para 33,3\%), resultando em uma pontuação atingida pelas empresas no total de 14 pontos ou $3,8 \%$ em 2008 e de 15 pontos ou 4,2\% em 2009. Percebe-se que nenhuma empresa divulgou todos os itens recomendados pelo CPC 07, sendo a Telemar e a M. Dias Branco ambas com 87,5\% de atendimento, e a Vale e a Souza Cruz ambas com 78,1\%, as empresas que apresentaram os melhores níveis de evidenciação sobre SAG nos dois períodos analisados. No outro extremo, as empresas com os piores níveis de evidenciação foram BM\&FBovespa, Duratex e Light, com 25\% de atendimento cada, e Sabesp e Elektro, ambas com $28,1 \%$ de atendimento. Constatou-se, assim, um nível de evidenciação geral bem inferior ao encontrado por Taveira (2009), cuja pesquisa indicou 48\% de atendimento dos requisitos de divulgação das SAGs nas demonstrações contábeis de 2008 das empresas listadas nos níveis diferenciados de governança da BM\&FBovespa, estudo com exercício social de análise anterior ao CPC 07 R1 (2010), assim como este que se apresenta. 
O item de divulgação mais apresentado refere-se à política contábil adotada para as SAGs, incluindo os métodos de apresentação adotados nas demonstrações financeiras (item 1), seguido dos itens 2 e 3, o que guarda consonância com os resultados de Taveira (2009), segundo os quais apenas os itens 1 e 2 apresentaram nível satisfatório de divulgação (evidenciação total).

Contudo, os itens 4, 6 e 7 foram os que apresentaram os piores níveis de evidenciação. Isso se justifica porque, no caso do item 4, a empresa pode ter cumprido todas as exigências, o que evitaria perda e/ou contingência em relação a SAG; no caso do item 6 , a empresa pode não possuir um incentivo a ser considerado no futuro; no caso dos itens 7 e 8 , a empresa pode não possuir SAGs não monetárias, o que não requer cálculo do valor justo ou quotas dos fundos de investimentos. Entretanto, ressalta-se que, ainda que a empresa não apresentasse tais situações, a mesma deveria evidenciar em Nota Explicativa tal fato, levando em conta a recomendação do CPC 07 (2008), como foi o caso das empresas que divulgaram a informação de não aplicação, sendo a evidenciação de tais itens considerada na pesquisa como Evidenciação Total. Um exemplo dessa divulgação está demonstrado no Quadro 3 com a evidenciação do item 4 pela empresa M. Dias Branco. Vale lembrar que o CPC 07(R1) (2010), que alterou o CPC 07 (2008), prescreve que as empresas devem divulgar, obrigatoriamente, apenas as informações citadas nos itens 1,2 e 3 a partir de 2010, porém o presente estudo analisa o período anterior ao CPC 07 (R1), publicado em 2010.

A Tabela 5 exibe a distribuição quantitativa e proporcional (\%) das empresas que em 2008 e 2009 apresentaram Evidenciação Total na avaliação dos itens de divulgação requisitados pelo CPC 07 (2008), por segmento de listagem da BM\&FBovespa.

Tabela 5: Distribuição quantitativa e proporcional das empresas que apresentaram Evidenciação Total, por item de divulgação e por segmento de listagem.

\begin{tabular}{|c|c|c|c|c|c|c|c|c|c|c|c|}
\hline \multicolumn{12}{|c|}{2008} \\
\hline Segmento de listagem & 1 & 2 & 3 & 4 & 5 & 6 & 7 & 8 & Total & Quantidade & Proporção (\%) \\
\hline Nível 1 & 7 & 6 & 5 & - & 4 & 1 & - & 3 & 26 & 9 & 36,1 \\
\hline Nível 2 & 1 & 1 & 1 & - & 1 & - & - & - & 4 & 1 & 50,0 \\
\hline Novo Mercado & 10 & 9 & 8 & 1 & 4 & - & - & 1 & 33 & 17 & 24,3 \\
\hline Outras & 17 & 12 & 10 & - & 7 & - & 1 & 1 & 48 & 19 & 31,6 \\
\hline TOTAL & 35 & 28 & 24 & 1 & 16 & 1 & 1 & 5 & 111 & 46 & 30,4 \\
\hline \multicolumn{12}{|c|}{2009} \\
\hline Segmento de listagem & 1 & 2 & 3 & 4 & 5 & 6 & 7 & 8 & Total & Quantidade & Proporção (\%) \\
\hline Nível 1 & 7 & 7 & 5 & - & 4 & 1 & - & 3 & 27 & 9 & 37,5 \\
\hline Nível 2 & 1 & 1 & 1 & - & 1 & - & - & - & 4 & 1 & 50,0 \\
\hline Novo Mercado & 9 & 9 & 9 & 1 & 3 & - & 1 & 1 & 33 & 15 & 27,5 \\
\hline Outras & 17 & 14 & 3 & - & 7 & - & 2 & 4 & 55 & 20 & 34,4 \\
\hline TOTAL & 34 & 31 & 26 & 1 & 15 & 1 & 3 & 8 & 119 & 45 & 33,3 \\
\hline
\end{tabular}

Fonte: Dados da pesquisa.

Os dados da Tabela 5 não apontam qualquer relação entre os segmentos de listagem e os níveis de divulgação das respectivas empresas, já que nos dois períodos analisados as empresas 
não integrantes dos três níveis diferenciados apresentaram melhor disclosure (31,6\% em 2008 e 34,4\% em 2009) do que as empresas do Novo Mercado (24,3\% em 2008 e 27,5\% em 2009), diferentemente da expectativa inicial dos autores, considerando o nível de transparência exigido pelas empresas desse segmento. Entretanto, constata-se que as empresas do Nível 2 apresentam melhor nível de evidenciação (50\% em 2008 e em 2009) do que as do Nível 1 (36,1\% em 2008 e $37,5 \%$ em 2009), corroborando as normas de adesão aos níveis diferenciados de governança da BM\&FBovespa. Observa-se ainda um maior atendimento dos itens de divulgação do CPC 07 (2008) pelas empresas dos Níveis 1 e 2 e daquelas não participantes dos segmentos diferenciados, em 2008 e 2009.

\subsection{Efeitos da Contabilização da SAG nos Indicadores Econômicos das Empresas, Segundo os Respectivos Setores de Atuação}

A Tabela 6 revela os efeitos econômicos da contabilização da SAG nas demonstrações contábeis de 2009 das empresas que receberam SAG no período (conforme Tabela 2), segundo os respectivos setores de atuação. Cabe lembrar que o exercício de 2009 foi selecionado como referência por apresentar maior representatividade das SAGs nas empresas pesquisadas, comparativamente ao exercício de 2008.

Tabela 6: ISAG e Indicadores Econômicos das empresas em 2009

\begin{tabular}{|c|c|c|c|c|c|c|c|c|c|c|}
\hline \multirow{2}{*}{$\begin{array}{l}\text { Setor de } \\
\text { atuação }\end{array}$} & \multirow{2}{*}{$\underset{(\%)}{\text { ISAG }}$} & \multicolumn{3}{|c|}{ ROA (\%) } & \multicolumn{3}{|c|}{ ROE (\%) } & \multicolumn{3}{|c|}{ ROS (\%) } \\
\hline & & $\begin{array}{c}\text { Situação } \\
\text { Atual }\end{array}$ & $\begin{array}{c}\text { Excluindo SAG } \\
\text { do Resultado }\end{array}$ & $\begin{array}{c}\text { Variação } \\
\text { Índice }\end{array}$ & $\begin{array}{c}\text { Situação } \\
\text { Atual }\end{array}$ & $\begin{array}{c}\text { Excluindo SAG } \\
\text { do Resultado }\end{array}$ & $\begin{array}{c}\text { Variação } \\
\text { Índice }\end{array}$ & $\begin{array}{c}\text { Situação } \\
\text { Atual }\end{array}$ & $\begin{array}{c}\begin{array}{c}\text { Excluindo SAG } \\
\text { do Resultado }\end{array} \\
\end{array}$ & $\begin{array}{c}\text { Variação } \\
\text { Índice }\end{array}$ \\
\hline Autoindústria & 0,5 & 5,6 & 5,4 & 0,1 & 17,5 & 17,1 & 0,4 & 7,3 & 7,2 & 0,2 \\
\hline Bens de Capital & 0 & 10,2 & 10,2 & 0 & 23,2 & 23,1 & 0,1 & 10,7 & 10,7 & 0 \\
\hline Bens de Consumo & 3,4 & 11,7 & 11,2 & 0,4 & 21,9 & 21,1 & 0,8 & 13 & 12,5 & 0,5 \\
\hline Eletroeletrônico & 0 & 8,4 & 8,3 & 0,1 & 22,1 & 21,8 & 0,3 & 4,3 & 4,2 & 0,1 \\
\hline Energia & 2,7 & 8,2 & 7,9 & 0,2 & 18 & 17,5 & 0,5 & 12 & 11,7 & 0,3 \\
\hline Mineração & 0 & 5,8 & 5,8 & 0 & 10,7 & 10,7 & 0 & 20,6 & 20,6 & 0 \\
\hline Papel e Celulose & 7,7 & 6,9 & 6,6 & 0,3 & 20 & 19,2 & 0,9 & 19,7 & 18,8 & 0,8 \\
\hline $\begin{array}{c}\text { Química e } \\
\text { Petroquímica }\end{array}$ & 4,5 & 4,2 & 3,8 & 0,4 & 14,5 & 13,1 & 1,3 & 2,4 & 2,2 & 0,2 \\
\hline Serviços & 0,2 & 7,9 & 7,8 & 0,1 & 43,1 & 42,6 & 0,6 & 31,1 & 30,7 & 0,4 \\
\hline $\begin{array}{l}\text { Siderurgia e } \\
\text { Metalurgia }\end{array}$ & 0,7 & 6,7 & 6,7 & 0 & 13,8 & 13,7 & 0,1 & 17,1 & 17 & 0,1 \\
\hline Telecomunicações & 0,3 & 1,1 & 0,9 & 0,1 & 3,1 & 2,7 & 0,3 & 1,2 & 1,1 & 0,1 \\
\hline Têxtil & 8,1 & 12,1 & 7,3 & 4,8 & 16,4 & 9,9 & 6,5 & 10 & 6 & 4 \\
\hline Transporte & 0,7 & 0,8 & 0,7 & 0,2 & 3 & 2,4 & 0,6 & 2,9 & 2,3 & 0,6 \\
\hline MÉDIA & 1,8 & 6,7 & 6,5 & 0,2 & 15,1 & 14,6 & 0,4 & 10,1 & 9,9 & 0,3 \\
\hline
\end{tabular}

A avaliação dos efeitos nos indicadores econômicos das empresas foi obtida por meio da análise setorial - comportando todos os setores de atuação com pelo menos uma empresa contemplada com SAG no exercício de 2009 - seguindo a sua aplicação em diversos estudos que abordaram o tema avaliação de empresas, como, por exemplo, os de Damodaran (2002), Liu, Nissim e Thomas (2002) e Saliba (2008). Além disso, Alford (1992) encontrou evidências de que a escolha de empresas comparáveis por setor eleva a precisão das previsões, ainda mais quando combinada com o ROE para empresas de grande porte, como as integrantes da amostra desta pesquisa.

Nessa perspectiva, conforme Tabela 6, observa-se que os maiores índices de SAG (ISAG) em 2009 foram obtidos pelos setores: Têxtil (8,1\%), Papel e Celulose (7,7\%) e Química e Petroquímica (4,5\%). Elucida-se que os maiores ISAGs no período foram alcançados por: 
CTEEP (34\%), Souza Cruz (26,2\%), Cemig (25,2\%), Coelba (19,1\%) e Coelce (13,5\%). Os setores Bens de Capital, Eletroeletrônico e Mineração registraram ISAG nulo, pelo fato de as empresas desses setores haverem recebido SAG em valores irrelevantes.

A análise de todos os setores de atuação com pelo menos uma empresa beneficiada com SAG no exercício de 2009 apontou um ISAG de 1,8\%, o que repercutiu em uma sensível variação dos índices econômicos ROA $(0,2 \%)$, ROE $(0,4 \%)$ e ROS $(0,3 \%)$. Quanto à variação dos índices econômicos, observa-se uma grande oscilação, dependendo do setor de atuação. Devido ao elevado ISAG, o setor Têxtil foi o mais impactado pela nova legislação contábil brasileira, em termos de rentabilidade em 2009, com variação de 4,8\% no ROA, 6,5\% no ROE e 4\% no ROS. Essa alteração representativa nos indicadores se dá, especialmente, devido à variação encontrada na Grendene, com 8,9\% no ROA, 10,73\% no ROE e 8,6\% no ROS. Além da Grendene, outras duas empresas também apresentaram elevada variação nos três índices econômicos analisados no período de 2009: M. Dias Branco (ROA 6,2\%, ROE 9,6\% e ROS 5,2\%), do setor Bens de Consumo; e Coelce (ROA 2,6\%, ROE 7,08\% e ROS 2,5\%), do setor Energia.

Do exposto, conclui-se que os resultados da análise econômica e do ISAG das empresas em 2009 apontam significativa alteração nos resultados econômicos evidenciados na DRE e na alta representatividade das SAGs no capital próprio das maiores empresas brasileiras. Esses resultados ratificam a afirmação de Tonetto Filho e Fregonesi (2010), de que a adoção das IFRS, por meio dos pronunciamentos técnicos do CPC implica em mudanças significativas nas informações contábeis, pois altera os critérios de reconhecimento e mensuração de alguns ativos e passivos, introduzindo os conceitos do common law, a essência das operações em detrimento da forma legal e o valor justo.

\subsection{Nível de Evidenciação versus Indicadores de SAG e de Rentabilidade das Empresas}

Para atender ao último objetivo da pesquisa, foi analisado se as empresas que receberam os maiores recursos de SAG e obtiveram os maiores retornos em 2009 são as que apresentaram o maior nível de evidenciação contábil. A Tabela 7 apresenta as informações sobre a representatividade do incentivo (ISAG), a variação dos indicadores de rentabilidade e o nível de evidenciação das empresas, levando em conta o setor de atuação.

Tabela 7: Indicadores Econômicos e Evidenciação por Setor de Atuação em 2009

\begin{tabular}{l|c|c|c|c|c}
\hline Setor de atuação & $\begin{array}{c}\text { ISAG } \\
\mathbf{( \% )}\end{array}$ & $\begin{array}{c}\text { Variação ROA } \\
\mathbf{( \% )}\end{array}$ & $\begin{array}{c}\text { Variação ROE } \\
\mathbf{( \% )}\end{array}$ & $\begin{array}{c}\text { Variação ROS } \\
\mathbf{( \% )}\end{array}$ & $\begin{array}{c}\text { Nível de evidenciação médio } \\
\text { das empresas do setor }\end{array}$ \\
\hline Energia & 2,7 & 0,2 & 0,5 & 0,3 & $28,9 \%$ \\
\hline Bens de Consumo & 3,4 & 0,4 & 0,8 & 0,5 & $43,8 \%$ \\
\hline Têxtil & 8,1 & 4,8 & 6,5 & 4 & $50,0 \%$ \\
\hline Telecomunicações & 0,3 & 0,1 & 0,3 & 0,1 & $42,5 \%$ \\
\hline Química e Petroquímica & 4,5 & 0,4 & 1,3 & 0,2 & $31,3 \%$ \\
\hline Papel e Celulose & 7,7 & 0,3 & 0,9 & 0,8 & $37,5 \%$ \\
\hline Transporte & 0,7 & 0,2 & 0,6 & 0,6 & $25,0 \%$ \\
\hline Siderurgia e Metalurgia & 0,7 & 0 & 0,1 & 0,1 & $12,5 \%$ \\
\hline Autoindústria & 0,5 & 0,1 & 0,4 & 0,2 & $43,8 \%$ \\
\hline Serviços & 0,2 & 0,1 & 0,6 & 0,4 & $18,8 \%$ \\
\hline Eletroeletrônico & 0 & 0,1 & 0,3 & 0,1 & $25,0 \%$ \\
\hline Bens de Capital & 0 & 0 & 0,1 & 0 & $37,5 \%$ \\
\hline Mineração & 0 & 0 & 0 & 0 & $62,5 \%$ \\
\hline MÉDIA & $\mathbf{1 , 8}$ & $\mathbf{0 , 2}$ & $\mathbf{0 , 4}$ & $\mathbf{0 , 3}$ & $\mathbf{3 3 , 3 \%}$ \\
\hline
\end{tabular}

Fonte: Dados da pesquisa. 
Conforme a Tabela 7, exceto pelo setor Têxtil que possui os maiores valores de SAG, a maior variação nos indicadores de rentabilidade analisados no período, e o maior nível de evidenciação (50,0\%), superior à média geral dos setores analisados no ano de 2009 (33,3\%), não é possível verificar uma relação entre o nível de evidenciação, o índice dos valores incentivados e a variação dos indicadores econômicos. Observa-se ainda que as empresas do setor de Mineração, que apresentam inexpressividade no ISAG tiveram o maior nível de evidenciação $(62,5 \%)$, acima da média geral; resultado representado pela presença da empresa Vale nesse setor.

A Tabela 8 segue a mesma lógica evidenciada na Tabela 7, mas considerando o nível de governança corporativa das empresas, representado pelo segmento de listagem na BM\&FBovespa.

Tabela 8: Indicadores Econômicos e Evidenciação por Nível de Governança em 2009

\begin{tabular}{c|c|c|c|c|c}
\hline Segmento de listagem & $\begin{array}{c}\text { ISAG } \\
(\%)\end{array}$ & $\begin{array}{c}\text { Variação ROA } \\
\mathbf{( \% )}\end{array}$ & $\begin{array}{c}\text { Variação ROE } \\
\mathbf{( \% )}\end{array}$ & $\begin{array}{c}\text { Variação } \\
\text { ROS (\%) }\end{array}$ & $\begin{array}{c}\text { Nível de evidenciação médio } \\
\text { das empresas do segmento }\end{array}$ \\
\hline Nível 1 & 2,3 & 0,1 & 0,1 & 0,2 & $37,5 \%$ \\
\hline Nível 2 & 0,8 & 0,2 & 0,7 & 1,0 & $50,0 \%$ \\
\hline Novo Mercado & 0,5 & 0,2 & 0,6 & 0,4 & $27,5 \%$ \\
\hline Outras & 1,8 & 0,2 & 0,5 & 0,3 & $34,4 \%$ \\
\hline MÉDIA & $\mathbf{1 , 8}$ & $\mathbf{0 , 2}$ & $\mathbf{0 , 4}$ & $\mathbf{0 , 3}$ & $\mathbf{3 3 , 3 \%}$ \\
\hline
\end{tabular}

Fonte: Dados da pesquisa.

De acordo com a Tabela 8, nota-se, em linhas gerais, que há possível relação, levando em conta o nível de governança corporativa das empresas, entre a variação dos indicadores econômicos e o segmento de listagem, visto que o Nível 2 foi o segmento com o maior índice de evidenciação e o segmento que sofreu maior variação nos indicadores econômicos, apesar de não ter apresentado o maior ISAG. Na análise das empresas do Nível 1, observa-se o maior ISAG $(2,3 \%)$ e o segundo nível de evidenciação médio (37,5\%), acima da média geral dos segmentos analisados no ano de 2009 (33,3\%).

\section{CONSIDERAÇÕES FINAIS}

O estudo objetivou verificar a divulgação das informações e os efeitos econômicos decorrentes do novo reconhecimento contábil das Subvenções e Assistências Governamentais (SAG) nas demonstrações contábeis das maiores empresas brasileiras de capital aberto. Para tanto, o nível de evidenciação foi analisado por meio da aplicação da Análise de Conteúdo das Notas Explicativas de 2008 e 2009, através de um check list, conforme as disposições do CPC 07, enquanto os seus efeitos econômicos foram mensurados por meio dos índices ROA, ROE, ROS e ISAG de 2009.

Em geral, os resultados obtidos forneceram subsídios para afirmar que, tanto em 2008 como em 2009, a maioria das empresas, do total de 88 empresas participantes da amostra, evidenciou o recebimento de SAG nos relatórios contábeis - o que justifica a realização deste estudo -, com predomínio das empresas dos setores de Energia, Bens de Consumo e 
Telecomunicações. Entretanto, referidas companhias apresentaram nível de evidenciação baixo, tendo atendido, em média, 30,4\% em 2008 e 33,3\% em 2009, resultando em uma pontuação obtida pelas empresas no total de 14 dentre a pontuação máxima de 368 pontos $(3,8 \%)$ em 2008 e de 15 dentre o máximo de 360 pontos (4,2\%) em 2009, dos requisitos de divulgação do CPC 07, como também não se constatou qualquer relação entre os níveis de divulgação das empresas e os respectivos segmentos de listagem na BM\&FBovespa. Além disso, quanto aos efeitos econômicos por conta das mudanças contábeis nas SAG, os resultados mostram uma variação positiva da rentabilidade e uma expressiva participação das SAGs no capital próprio das empresas.

Com base nas análises realizadas na amostra das 88 maiores companhias abertas nãofinanceiras, pelo critério valor de mercado, listadas no anuário Exame Melhores e Maiores 2010, foi possível inferir as conclusões a seguir.

No que tange ao primeiro objetivo específico, constatou-se que 51,1\% das empresas em 2008 e 52,3\% em 2009 evidenciaram possuir algum tipo de SAG nas demonstrações contábeis, o que corrobora alguns estudos empíricos anteriores, que atestaram a relevância das SAGs para as empresas brasileiras. Observou-se ainda que (i) a maioria das empresas recebeu SAG oriundas da União, com destaque para os incentivos nos impostos federais, cuja maior parte corresponde à renúncia fiscal do imposto de renda de pessoa jurídica; (ii) nenhuma empresa evidenciou o recebimento de SAG oriunda de governo municipal; e (iii) algumas empresas acumularam em um mesmo exercício o recebimento de SAG dos governos federal e estadual; (iv) os quatro setores que receberam as maiores quantidades de SAG foram Energia, Bens de Consumo, Telecomunicações e Siderurgia e Metalurgia, enquanto em montante financeiro foram mais beneficiadas as empresas dos setores Têxtil, Energia, Bens de Consumo, Telecomunicações e Química e Petroquímica.

Quanto ao segundo objetivo específico, verificou-se que o nível de atendimento dos requisitos de divulgação do CPC 07 das empresas que receberam SAG foi relativamente baixo nos dois períodos analisados, sendo possível observar uma pequena melhora em 2009. Também constatou-se que (i) nenhuma empresa divulgou todos os itens recomendados pelo CPC 07; (ii) os itens 1, 2 e 3 obtiveram os melhores níveis de evidenciação, sendo os únicos prescritos no CPC 07(R1) (2010); e (iii) apesar das limitações da análise, não foi constatada qualquer relação entre os segmentos de listagem das empresas e os níveis de evidenciação sobre SAG das respectivas empresas, já que em ambos os períodos as empresas não integrantes dos três níveis diferenciados de governança corporativa apresentaram melhor disclosure do que as do Novo Mercado.

Com relação ao terceiro objetivo específico, os resultados da análise dos efeitos da nova prática de reconhecimento da SAG nos indicadores econômicos das empresas em 2009, demonstram um ISAG de $1,8 \%$, e uma variação dos índices econômicos ROA, ROE e ROS em $0,2 \%, 0,4 \%$ e $0,3 \%$, respectivamente. Dessa forma, especialmente em alguns setores de atuação, pode-se inferir que, devido à recente mudança nos critérios de registro contábil das SAGs, (i) modificou-se o nível de rentabilidade das empresas; e (ii) confirmou-se a significativa representatividade das SAGs no capital próprio das empresas.

Assim, respondendo ao quarto e último objetivo específico, verificou-se que, levando em conta o setor de atuação das empresas, não há uma possível relação entre o nível de evidenciação, o ISAG e a variação dos indicadores econômicos, exceto no setor Têxtil. Quanto 
à análise das empresas segundo o nível de governança, foi possível notar relação entre a variação dos indicadores de rentabilidade e o nível de evidenciação, principalmente quando analisado o segmento de listagem diferenciado de governança corporativa Nível 2 da BM\&FBovespa.

Importa lembrar que a análise realizada, ainda que embrionária, sinalizou importantes pontos sobre a expressividade das SAGs nas empresas brasileiras, e que apesar do seu impacto econômico, estas assinalaram baixo nível de evidenciação contábil, comparativamente ao preconizado no CPC 07, indicando que as empresas ainda têm um longo caminho a trilhar até aderirem à prescrição normativa. Por fim, cabe elucidar que apesar do rigor científico aplicado nesta pesquisa qualitativa, salienta-se a importância de que em estudos futuros sejam empregadas técnicas estatísticas robustas, a fim de se discernir, com abordagem quantitativa, sobre os efeitos das mudanças das práticas contábeis de empresas brasileiras na sua avaliação econômico-financeira.

\section{REFERÊNCIAS}

ALENCAR, R. C.; PIMENTEL, F. S.; MOTA FILHO, C. S. IAS 20 - Subvenção e assistência governamentais. In: Ernst \& Young e Fipecafi. Manual de normas internacionais de contabilidade: IFRS versus normas brasileiras, v. 2. São Paulo: Atlas, 2010.

ALFORD, A. W. The effect of the set of comparable firms on the accuracy of the price-earnings valuation method. Journal of Accounting Research, v. 30, n. 1, p. 94-108, 1992.

ALVES, C. V. O.; CARVALHO, L. N. G.; SLOMSKI, V. O reconhecimento das contribuições, doações e subvenções nas entidades do terceiro setor: uma comparação entre os US-GAAP, normas do IASB e do CFC. In: CONGRESSO USP DE CONTROLADORIA E CONTABILIDADE, 4 , São Paulo, Anais... São Paulo: FEA/USP, 2004.

BARDIN, L. Análise de conteúdo. Lisboa: Edições 70, 2004.

BM\&FBOVESPA. Governança corporativa. Disponível em: http://www.bmfbovespa.com.br/ciaslistadas/consultas/governanca-corporativa/governanca-corporativa.aspx?Idioma=pt-br. Acesso em: 19 nov. 2010.

BRASIL. Lei $n^{\circ}$ 6.404, de 15 de dezembro de 1976. Dispõe sobre as sociedades por ações. Disponível em: http://www.planalto.gov.br/ccivil.../Leis/L6404consol.htm. Acesso em: 19 set. 2010.

. Lei $n^{\circ} 11.638$, de 28 de dezembro de 2007. Altera e revoga dispositivos da Lei $n^{\circ}$ $\overline{6.404, \text { de }} 15$ de dezembro de 1976, e da Lei $\mathrm{n}^{\circ}$ 6.385, de 7 de dezembro de 1976, e estende às sociedades de grande porte disposições relativas à elaboração e divulgação de demonstrações financeiras. Disponível em: http://www.planalto.gov.br/ccivil 03/_ato2007-2010/2007/Lei/L11638.htm. Acesso em: 19 set. 2010.

. Lei $n^{\circ} 11.941$, de 27 de maio de 2009. Altera a legislação tributária federal relativa ao parcelamento ordinário de débitos tributários, institui regime tributário de transição e dá outras providências. Disponível em: http://www.planalto.gov.br/../2009/lei/111941.htm. Acesso em: 19 set. 2010. 
CHAGAS, M. J. R. et al. Evidenciação das subvenções e assistências governamentais recebidas pelas OSCIPs: uma análise empírica nos estados da Paraíba e do Rio Grande do Norte. In: SEMINÁRIOS EM ADMINISTRAÇÃO - SEMEAD, 13., São Paulo, Anais... São Paulo: FEA/ USP, 2010.

CVM. Demonstrações financeiras padronizadas. Disponível em: http://www.cvm.gov.br/. Acesso em: 15 set. 2010 .

. Instrução $C V M n^{\circ} 469$, de 2 de maio de 2008. Dispõe sobre a aplicação da Lei $\mathrm{n}^{\circ} 11.638$, de 28 de dezembro de 2007. Altera as Instruções CVM nº 247, de 27 de março de 1996, e 331, de 4 de abril de 2000. Disponível em: http://www.normaslegais.com.br/legislacao/instrucaocvm469_2008. htm. Acesso em: 10 jun. 2010.

.Deliberação $\mathrm{CVMn}^{\circ} 555$, de 12 de novembro de 2008. Aprova o Pronunciamento Técnico CPC 07 do Comitê de Pronunciamentos Contábeis, que trata de Subvenções e Assistências Governamentais. Disponível em: http://www.normaslegais.com.br/legislacao/deliberacaocvm555_2008. htm. Acesso em: 10 jun. 2010.

.Deliberação $C V M n^{\circ}$ 646, de 2 de dezembro de 2010. Aprova o Pronunciamento Técnico CPC 07(R1) do Comitê de Pronunciamentos Contábeis, que trata de subvenção e assistência governamentais. Disponível em: http:/www.cvm.gov.br/asp/cvmwww/atos/Atos_Redir.asp?Tipo=D\&File $=\% 5$ Cdeli $\% 5$ Cdeli646.doc. Acesso em: 15 dez. 2010.

CPC. Pronunciamento Técnico CPC 07 - Subvenção e assistência governamental, de 3 de outubro de 2008. Disponível em: http://www.cpc.org.br/pdf/CPC 07.pdf. Acesso em: 4 jul. 2010.

Pronunciamento Técnico CPC 07 - Subvenção e assistência governamentais, de 3 de outubro de 2008. Relatório de audiência pública. Disponível em: http://www.cpc.org.br/pdf/ Relatorio_da_audpub_CPC 07.pdf. Acesso em: 4 jul. 2010.

Pronunciamento Técnico CPC 07(R1) - Subvenção e assistência governamentais, de 5 de novembro de 2010. Disponível em: http://www.cpc.org.br/pronunciamentosIndex.php. Acesso em: 15 dez. 2010.

CFC. Resolução $n^{\circ} 1.143$, de 28 de novembro de 2008. NBC T 19.4 Disponível em http://www. cfc.org.brl. Acesso em: 28 jul. 2010.

DAMODARAN, A. A face oculta da avaliação: avaliação de empresas da velha tecnologia, da nova tecnologia e da nova economia. São Paulo: Makron Books, 2002.

FORMIGONI, H. A influência dos incentivos fiscais sobre a estrutura de capital e a rentabilidade das companhias abertas brasileiras não financeiras. 2008. 192 f. Tese (Doutorado em Ciências Contábeis) - Programa de Pós-Graduação em Ciências Contábeis, Universidade de São Paulo, São Paulo, 2008.

GRUBER, R. R.; GIMENES, R. M. T.As cooperativas agropecuárias frente à competitividade das sociedades anônimas: aspectos econômicos e jurídicos. In: ENCONTRODEPESQUISADORES LATINO-AMERICANOS DE COOPERATIVISMO, 5., Anais ... Ribeirão Preto, São Paulo, Brasil, 2008.

IUDÍCIBUS, S. et al. Manual de contabilidade societária: aplicável a todas as sociedades de 
acordo com as normas internacionais e do CPC. São Paulo: Atlas, 2010.

. Análise de balanços. 10. ed. São Paulo: Atlas, 2010.

LIU, J.; NISSIM, D.; THOMAS, J. Equity valuation using multiples. Journal of Accounting Research, v. 40, n. 1, p. 135-172, 2002.

NOGUEIRA JÚNIOR, E.; JUCÁ, M. N.; MACEDO, M. A. S. O impacto da harmonização das práticas contábeis brasileiras às internacionais na relação entre o lucro líquido e o fluxo de caixa operacional. In: CONGRESSO USP DE CONTROLADORIA E CONTABILIDADE, 10., São Paulo, Anais... São Paulo: FEA/USP, 2010.

RECH, I. J. Aderência das empresas do setor agropecuário às normas internacionais de contabilidade: uma pesquisa empírica no âmbito do estado de Mato Grosso. 2006. $140 \mathrm{f}$. Dissertação (Mestrado em Ciências Contábeis) - Programa Multiinstitucional e Inter-Regional de Pós-Graduação em Ciências Contábeis da Universidade de Brasília - UNB, Brasília, 2006.

SALIBA, R. V. Aplicação de modelos de avaliação por múltiplos no Brasil. Revista Brasileira de Finanças, v. 6, n. 1, p. 13-47, 2008.

SANTOS, D. F. L. A influência da inovação no desempenho das firmas no Brasil. 2009. 315 f. Tese (Doutorado em Administração de Empresas) - Centro de Ciências Sociais Aplicadas. Universidade Presbiteriana Mackenzie, São Paulo, 2009.

TAVEIRA, J. H. P. S. Conformidade do disclosure das subvenções governamentais nas empresas de capital aberto. 2009. 78 f. Dissertação (Mestrado Profissionalizante em Administração) Programa de Pós-Graduação e Pesquisa em Administração e Economia, Faculdade de Economia e Finanças IBMEC, Rio de Janeiro, 2009.

TONETTO FILHO, V.; FREGONESI, M. S. F. A. Análise da variação dos índices de endividamento e liquidez e do nível de divulgação das empresas do setor de alimentos processados com a adoção das normas internacionais. In: CONGRESSO USP DE CONTROLADORIA E CONTABILIDADE, 10., São Paulo, Anais... São Paulo: FEA/USP, 2010. 


\section{ENDEREÇO DOS AUTORES:}

\section{Débora Queiroz Oliveira Feres Ribeiro}

Universidade Federal do Ceará, Faculdade de Economia Administração Atuária e Contabilidade, Departamento de Contabilidade

Av. da Universidade 2431 - Benfica

60020-180 - Fortaleza, CE - Brasil

\section{Alessandra Vasconcelos Gallon}

Universidade Federal do Ceará, Faculdade de Economia Administração Atuária e Contabilidade, Departamento de Contabilidade.

Av. da Universidade 2431 - Benfica

60020-180 - Fortaleza, CE - Brasil

\section{Márcia Martins Mendes De Luca}

Universidade Federal do Ceará, Faculdade de Economia Administração Atuária e Contabilidade, Departamento de Contabilidade.

Avenida da Universidade, 2486 - Benfica

60020-180 - Fortaleza, CE - Brasil 